\title{
Acute effect of intensity and volume during strength training on sensation of pleasure, rating of perceived exertion, and pain in trained men
}

original paper

() Wroclaw University of Health and Sport Sciences

DOI: https://doi.org/10.5114/hm.2023.107245

\section{GUSTAVO CÉSAR VASCONCELOS ${ }^{1}$, IGOR DAMORIM ${ }^{2}$, TONY SANTOS ${ }^{2}$, DALTON LIMA-JUNIOR ${ }^{3}$, LEONARDO FORTES ${ }^{3}$}

${ }^{1}$ Federal University of São Paulo, São Paulo, Brazil

${ }^{2}$ Federal University of Pernambuco, Recife, Brazil

${ }^{3}$ Federal University of Paraíba, João Pessoa, Brazil

\section{ABSTRACT}

Purpose. The purposes of this study were: (a) to compare the sensation of pleasure, rating of perceived exertion (RPE), and pain in different volumes (volitional failure [VF] vs. fixed repetitions [FR]), equalizing the intensity; and (b) to compare the sensation of pleasure, RPE, and pain in different intensities (40\%, 60\%, and $80 \%)$ of one-repetition maximum (1RM), with equalization of training volume.

Methods. A total of 12 trained men (aged $24.9 \pm 4.3$ years) performed 3 sets of seated row, leg press $180^{\circ}$, and chest press at 3 different intensities $(40 \%, 60 \%$, and $80 \% 1 \mathrm{RM})$ for both training strategies (VF vs. FR).

Results. There was a decrease in pleasure and an increase in RPE and pain in VF training sessions at intensities of $40 \%$ and $60 \% 1 \mathrm{RM}$ compared with FR. However, no difference was observed for the intensity of $80 \% 1 \mathrm{RM}$ for pleasure. A doseresponse effect was revealed in the comparison of intensities for pain and RPE. In turn, no effect was found for pleasure.

Conclusions. VF training sessions decreased responses regarding pleasure, as well as increased RPE and perceived pain for the intensities of $40 \%$ and $60 \% 1 \mathrm{RM}$ when compared with the same intensity in FR among trained men. Different intensities were not able to change the sensation of pleasure.

Key words: training, repetition failure, psychophysiological, discomfort, behaviour

\section{Introduction}

Rating of perceived exertion (RPE) is a reliable and feasible measurement to assess training intensity [1]. High RPE scores are normally observed with increased intensity during aerobic exercise. However, RPE in strength training is influenced by one-repetition maximum percentage (1RM\%) [2], and number of sets [3] and repetitions [4]. Therefore, RPE indicates central and peripheral changes due to psychological, pathological, or physiological factors $[5,6]$.

The relationship between RPE and other psychophysiological factors such as pleasure/displeasure has previously been observed [7]. The sensation of pleasure seems to decrease in high-intensity training [8]. However, this pleasure modulation pattern was only revealed for continuous aerobic exercises [9]. Therefore, it is still not possible to establish a theoretical basis which explains the mechanisms presented in modulating this variable during strength training [10-12]. For example, Portugal et al. [12] investigated 3 intensities $(40 \%, 60 \%$, and $80 \% 1 \mathrm{RM})$, equalizing volume in 8 fixed repetitions (FR) for all intensities. Moreover, a decrease in the sensation of pleasure was only observed when high intensity ( $80 \% 1 \mathrm{RM})$ was compared with the control condition (without intervention) in trained men. The sensation of pleasure decreased in women in training performed at $70 \% 1 \mathrm{RM}$ when compared with $40 \%$ [11].

It is possible that the training configuration adopted in those studies (different $1 \mathrm{RM} \%$ for a fixed number of repetitions) did not allow the investigated partici-

Correspondence address: Gustavo C. Vasconcelos, Department of Physical Education, Federal University of São Paulo, Doutor Dolzani, 344, Jardim da Glória - SP, Brazil, e-mail: gustav.cesar@hotmail.com

Received: January 8, 2021

Accepted for publication: May 11, 2021

Citation: Vasconcelos GC, Damorim I, Santos T, Lima-Junior D, Fortes L. Acute effect of intensity and volume during strength training on sensation of pleasure, rating of perceived exertion, and pain in trained men. Hum Mov. 2023;24(1):104-113; doi: https://doi.org/10.5114/hm.2023.107245. 
pants to experience different sensations during the training sessions, maintaining almost the same feeling of pleasure [3]. This might happen because low intensities and low training volume do not seem to influence pleasure modulation, keeping it positive [13]. For example, performing 8 repetitions at $80 \% 1 \mathrm{RM}$ is closer to exhaustion and highest in total work (resistance $x$ number of repetitions $\times$ number of sets) than $40 \% 1 \mathrm{RM}$ to a similar repetition number [4]. In addition to presenting different metabolic, neuromuscular, and cardiovascular responses [14], this training configuration is in disagreement with the recommendations of the American College of Sports Medicine for trained men, which predict repetitions until concentric failure for a maximal strength percentage or repetition zones between 8 and 12 [15].

The use of performance sets to volitional failure (VF) during strength training sessions was popularized by the theory of achieving better results in muscle strength compared with submaximal training [16]. However, no difference was observed between conditions for increased strength compared with submaximal exercise [17]. Therefore, the comparison of different training strategies (VF vs. FR) allows different psychological responses, as seen in studies evaluating RPE [4]. In addition, the relationship between RPE and pain perception has been verified at different intensities [18]. It is thus possible to hypothesize that the training configuration cited in the previous studies did not clearly show the modulation of this variable for the population of trained men. Furthermore, the intensity management model outlines the use of tests that evaluate maximum dynamic force, which presents a limited practical application, and this kind of prescription is not part of the routine of strength training practitioners.

Therefore, it is possible that the VF strategy might generate different responses regarding pleasure in trained men compared with FR. In this sense, it seems interesting to compare VF vs. FR in order to better understand affective responses. The relevance of this research is also supported by the intention to incorporate an understanding of modulating pleasure in the strength training prescription guidelines [19]. Therefore, the objectives of the present study are: (a) to compare the sensation of pleasure, RPE, and pain in different volumes (VF vs. FR), equalizing the intensity; and (b) to compare the sensation of pleasure, RPE, and pain at different intensities (40\%, 60\%, and 80\% 1RM), with training volume equalization. The hypotheses of the study are that pleasure will decrease in VF, as RPE and perception of pain will increase; when compared with intensities ( $40 \%$ vs. $60 \%$ vs. $80 \% 1 \mathrm{RM}$ ), pleasure would not decrease and RPE would have a dose-response effect.

\section{Material and methods}

\section{Participants}

A total of 18 participants were non-probabilistically selected. Nevertheless, only 12 trained men completed all steps of the study. Everyone had strength training experience of at least 6 months. The subjects were recruited through invitations made by word-of-mouth at the university and through advertisements published on social media. We included individuals who did not present a history of musculoskeletal injuries and did not use psychoactive or ergogenic nutritional drugs which could interfere in the study. The data were collected from an anamnesis. Participants who did not carry out all the visits were excluded. The subjects were instructed to maintain their usual activities, as well as not to alter their diet during the tests.

\section{Experimental design}

The cross-over study required 9 visits. The participants were informed about the procedures in the first visit. Next, they were familiarized with the perceptive scales: effort, sensation, pain, and the 10-repetition maximum (10RM) tests. The 10RM test was replicated on the second and third visits to establish its reproducibility. Thus, we minimized any prescription error of 10RM. Then, the acute effects of 3 intensities $(40 \%, 60 \%$, and $80 \% 1 \mathrm{RM})$ were investigated between the fourth and ninth visits, adopting VF or FR. There were 2-7-day intervals between the visits. The dependent variables were evaluated before, after the end of each set (not exceeding $10 \mathrm{~s}$ ), and after $15 \mathrm{~min}$ utes and 30 minutes of the training session. The main outcomes of this study were RPE, perception of pain, and sensation of pleasure during strength training.

\section{Measures}

\section{Anthropometry and body composition}

The anthropometric measures followed the recommendations of the International Society for the Advancement of Kinanthropometry [20] for body mass (portable scales PL 200, Filizola SA, São Paulo, Brazil, precision of $0.1 \mathrm{~kg}$ ), height (professional stadiometer Sanny, São Paulo, Brazil, $0.1 \mathrm{~cm}$ precision), 3 skinfolds [21], and fat percentage by the Siri equation [22]. 
G.C. Vasconcelos, I. Damorim, T. Santos, D. Lima-Junior, L. Fortes, The pleasure in strength training

\section{0-repetition maximum test}

The 10RM test was used to detect muscle strength. The exercises performed were: seated row, leg press $180^{\circ}$, and chest press $\left(\right.$ Matrix $\left.^{\circledR}\right)$. The test was carried out in 3 visits, with intervals of 48 hours in an attempt to reduce learning effects of motor gestures. Up to 3 attempts were made for each exercise to stipulate 10RM in a circuit design with a 15-minute interval between trials of the same exercise and a 5-minute interval for the different exercises. The following strategies were adopted to minimize the margin of error: (a) standardization of exercise technique and data collection; (b) specific warm-up at $50 \% 1 \mathrm{RM}$, in accordance with the value indicated by the individual; (c) corrections made on the technique; and (d) verbal encouragement to all participants. The individuals performed each exercise until they were unable to accomplish the movement as described by the evaluator. The equation used to predict 1RM for lower limbs was as follows [23]:

\section{$1 \mathrm{RM}=(0.0333 \times$ repetitions $) \times$ submaximal load + submaximal load}

For upper limbs, we used the equation by Adams [24], in accordance with the findings by Menêses et al. [25]:

$$
\begin{gathered}
1 \mathrm{RM}=\text { submaximal load } /[100-(2 \times \text { repetitions })] \\
\times 100
\end{gathered}
$$

\section{Psychometric scales}

The sensation of pleasure was quantified by a feeling scale [26] used to register the affective valence (pleasure and displeasure), consisting of 11 points with single items, with the polarity ranging from +5 (very good) to -5 (too bad). The perception of pain was quantified with a pain scale of 10 items [27]. The 10-point Borg Category-Ratio (CR10) Scale [28] was used to measure RPE. This instrument is composed of 11 points, with anchors varying from 0 (minimum effort) to 10 (maximum effort), and is a potentially effective scale for monitoring exercise intensity. After 30 minutes of session training, we asked each subject: 'How would you rate your effort?' [29].

\section{Strength training protocol}

The strength training protocol was composed of 3 exercises (seated row, leg press $180^{\circ}$, and chest press), always in the same order, with 3 sets for each exercise.
The subjects underwent a standardized warm-up of $10-15$ repetitions before each exercise. In the VF training, a maximum number of repetitions were performed for the intensities of $40 \%, 60 \%$, and $80 \% 1 \mathrm{RM}$. The FR training was implemented in a number of 8 repetitions for the intensities of $40 \%, 60 \%$, and $80 \% 1 \mathrm{RM}$. Two minutes of passive interval between the sets and exercises were assumed in both strategies. The number of repetitions for each set in the training sessions lasted until the concentric failure in each visit. The exercise was conducted until the concentric failure, and the correct way to perform the exercises was stipulated for everyone, although the execution time was not determined. The sensation of pleasure, pain, and RPE were measured $15 \mathrm{~s}$ before and after each set. The total work was quantified as resistance $\times$ sets $\times$ repetitions.

\section{Data analysis}

Participant characterization data were reported as average and standard deviation. The Shapiro-Wilk test was performed to evaluate normality. Levene's test assessed homoscedasticity, and data sphericity was verified by Mauchly's test. A two-way repeated measures ANOVA test was used to compare the mean responses of the final of each set in the variables: sensation of pleasure, pain, and RPE: (a) to analyse the differences between strategy and moment [(VF vs. FR) vs. (before the experiment, between all sets, and after the experiment)] at each investigated intensity $(40 \%, 60 \%$, and $80 \% 1 \mathrm{RM}$ ), with intensity equalization followed by posthoc Newman-Keuls test; (b) to analyse the differences between intensity vs. moments [ $[40 \%, 60 \%$, and $80 \%$ $1 \mathrm{RM})$ vs. (before the experiment, between all sets, and after the exercises)], with volume equalization (8 FR) followed by post-hoc Newman-Keuls test; and (c) to analyse the number of repetitions for sets and exercises. In addition, a one-way ANOVA was conducted to compare differences between total work for the strategies (VF vs. FR). The effect size (ES) was used to point out differences from the practical point of view. The following criteria were adopted, in accordance with Rhea [30]: $d<0.35$ : trivial ES, $0.35 \leq d<0.8$ : low $E S$, $0.8 \leq d<1.5$ : moderate ES, and $d \geq 1.5$ : large ES. Intraclass correlation coefficients and percentage coefficients of variation were used to determine relative and absolute test-retest reliability for 10RM. All data were processed with the Statistica 7.0 software. A significance level of $5 \%$ was adopted. 


\section{Ethical approval}

The research related to human use has complied with all the relevant national regulations and institutional policies, has followed the tenets of the Declaration of Helsinki, and has been approved by the Ethics Committee of the Health Sciences Centre of the Federal University of Pernambuco (CAAE 63080616.8.0000. 5208).

\section{Informed consent}

Informed consent has been obtained from all individuals included in this study.

\section{Results}

A total of 12 trained men of the 18 individuals recruited (age: $24.9 \pm 4.3$ years, body mass: $72.2 \pm 3.5 \mathrm{~kg}$, and fat: $18 \pm 6.4 \%$ ) completed all visits, performing the $10 \mathrm{RM}$ test (seated row: $71.3 \pm 4.3$, leg press $180^{\circ}$ : $74.5 \pm 3.5$, and chest press: $77.3 \pm 8.5$ ). Table 1 shows the results analysed by two-way ANOVA of the number of repetitions for sets and exercises (seated row, leg press $180^{\circ}$, and chest press) at the intensities of $40 \%$, $60 \%$, and $80 \%$ of $1 \mathrm{RM}$ for the VF strategy. Table 2 presents the total work for each exercise in the 2 con-

Table 1. Number of repetitions (mean \pm standard deviation) per set and exercise

\begin{tabular}{|c|c|c|c|c|}
\hline \multirow{2}{*}{ Intensity and exercise } & \multicolumn{3}{|c|}{ Volitional failure } & \multirow{2}{*}{$\begin{array}{c}p \\
\text { Moment }\end{array}$} \\
\hline & Set 1 & Set 2 & Set 3 & \\
\hline \multicolumn{5}{|l|}{$40 \%$ of $1 \mathrm{RM}$} \\
\hline Seated row & $36.0 \pm 6.1$ & $25.5^{\mathrm{a}} \pm 3.9$ & $21.2^{\mathrm{b}} \pm 2.6$ & $<0.001$ \\
\hline Leg press & $28.9 \pm 5.0$ & $18.2^{\mathrm{a}} \pm 4.2$ & $15.9^{b} \pm 1.9$ & $<0.001$ \\
\hline Chest press & $35.9 \pm 7.6$ & $19.5^{\mathrm{a}} \pm 4.5$ & $16.4^{\mathrm{a}} \pm 4.6$ & $<0.001$ \\
\hline \multicolumn{5}{|l|}{$60 \%$ of $1 \mathrm{RM}$} \\
\hline Seated row & $20.7 \pm 2.7$ & $14.6^{\mathrm{a}} \pm 2.3$ & $11.8^{\mathrm{b}} \pm 1.7$ & $<0.001$ \\
\hline Leg press & $20.1 \pm 4.3$ & $13.3^{\mathrm{a}} \pm 2.7$ & $11.3^{\mathrm{a}} \pm 2.7$ & $<0.001$ \\
\hline Chest press & $20.8 \pm 5.9$ & $11.5^{\mathrm{a}} \pm 3.0$ & $7.6^{\mathrm{b}} \pm 1.4$ & $<0.001$ \\
\hline \multicolumn{5}{|l|}{$80 \%$ of $1 \mathrm{RM}$} \\
\hline Seated row & $10.3 \pm 2.1$ & $8.8^{\mathrm{a}} \pm 1.4$ & $7.5^{\mathrm{b}} \pm 1.4$ & $<0.001$ \\
\hline Leg press & $8.9 \pm 1.8$ & $6.9^{\mathrm{a}} \pm 1.5$ & $6.6^{\mathrm{a}} \pm 1.3$ & $<0.001$ \\
\hline Chest press & $9.3 \pm 1.9$ & $8.3^{\mathrm{a}} \pm 1.6$ & $6.1^{\mathrm{b}} \pm 1.3$ & $<0.001$ \\
\hline
\end{tabular}

The mean number of repetitions was not included for the fixed repetition strategy because there was no variation. $1 \mathrm{RM}$ - one-repetition maximum

${ }^{\mathrm{a}} p<0.05$ in relation to set $1,{ }^{\mathrm{b}} p<0.05$ in relation to set 2

Table 2. Descriptive values of total work (mean \pm standard deviation) per exercise

\begin{tabular}{|c|c|c|c|}
\hline \multirow{2}{*}{ Intensity and exercise } & \multicolumn{2}{|c|}{ Total work } & \multirow{2}{*}{$\begin{array}{c}p \\
\text { Group }\end{array}$} \\
\hline & Volitional failure & Fixed repetition & \\
\hline \multicolumn{4}{|l|}{$40 \%$ of $1 \mathrm{RM}$} \\
\hline Seated row & $2872.3 \pm 484.3$ & $836.0 * \pm 111.2$ & $<0.001$ \\
\hline Leg press & $3144.9 \pm 834.7$ & $1173.8^{*} \pm 284.7$ & $<0.001$ \\
\hline Chest press & $2815.8 \pm 713.5$ & $912.3^{*} \pm 105.2$ & $<0.001$ \\
\hline \multicolumn{4}{|l|}{$60 \%$ of $1 \mathrm{RM}$} \\
\hline Seated row & $2452.1 \pm 516.8$ & $1254.6^{*} \pm 172.0$ & $<0.001$ \\
\hline Leg press & $2983.8 \pm 633.2$ & $1695.2 * \pm 462.0$ & $<0.001$ \\
\hline Chest press & $2211.8 \pm 428.28$ & $1354.1 * \pm 199.4$ & $<0.001$ \\
\hline \multicolumn{4}{|l|}{$80 \%$ of $1 \mathrm{RM}$} \\
\hline Seated row & $1823.9 \pm 272.4$ & $1718.2 * \pm 216.3$ & $<0.001$ \\
\hline Leg press & $2074.5 \pm 457.6$ & $2263.1 \pm 563.0$ & 0.380 \\
\hline Chest press & $1729.6 \pm 225.9$ & $1822.1 \pm 240.3$ & 0.522 \\
\hline
\end{tabular}

1RM - one-repetition maximum

${ }^{*} p<0.05$ 


\section{HUMAN MOVEMENT}

G.C. Vasconcelos, I. Damorim, T. Santos, D. Lima-Junior, L. Fortes, The pleasure in strength training

ditions (VF vs. FR). The intraclass correlation coefficient and coefficient of variation for 10RM were 0.99 and 0.3 , respectively.

\section{Volitional failure $\times$ fixed repetition}

\section{Sensation of pleasure}

Figure 1 shows the results analysed by two-way repeated measures ANOVA for each intensity $(40 \%, 60 \%$, and $80 \% 1 \mathrm{RM}$ ). An interaction between strategy (VF vs. FR) vs. moment (before the experiment, between all sets, and after the experiment) $\left(\mathrm{F}_{(11,143)}=2.12, p=0.022\right.$,

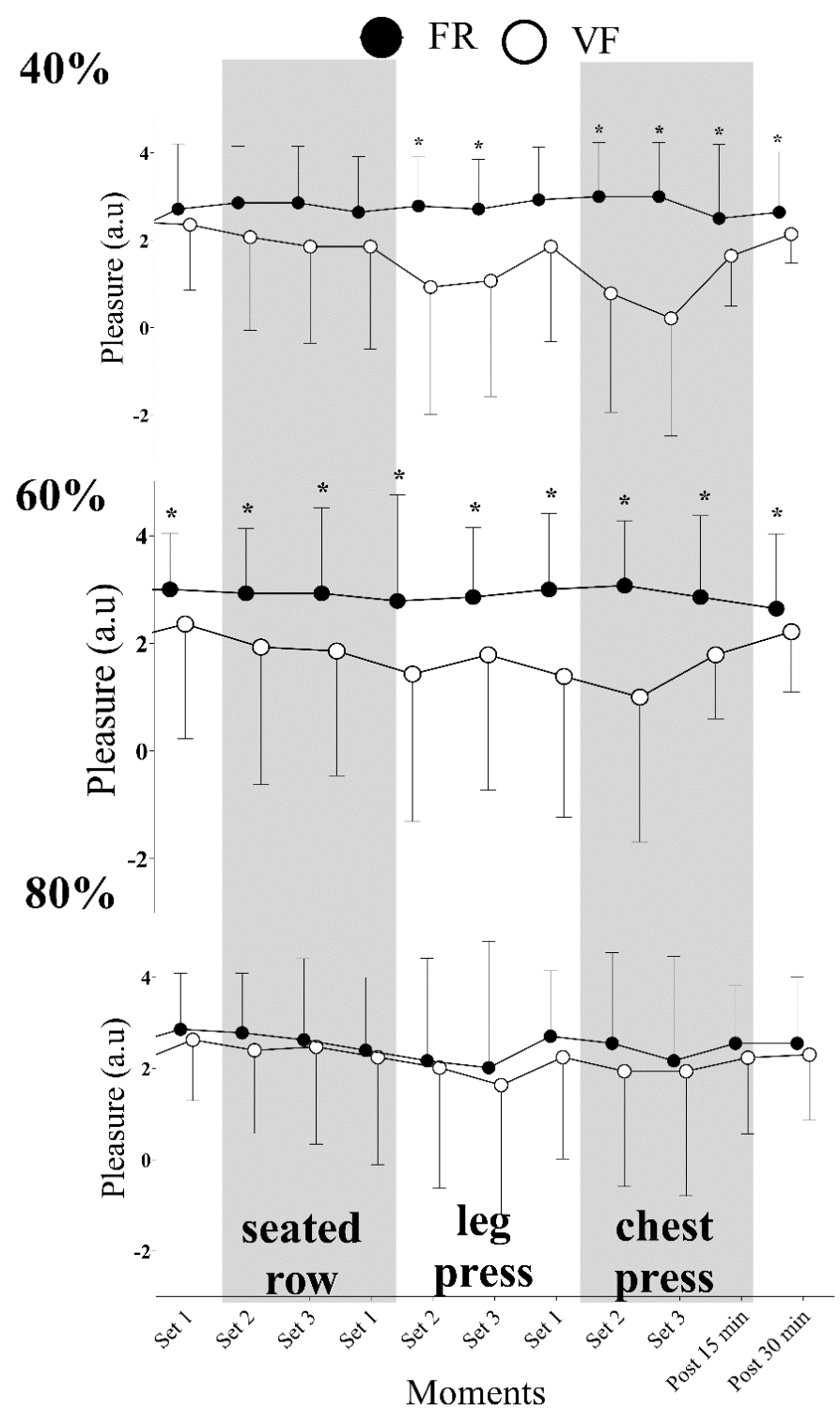

FR - fixed repetition, VF - volitional failure, a.u. - arbitrary unit * The moment between strategies was significantly different $(p<0.05)$

Figure 1. Comparison of pleasure in VF vs. FR strategies at the intensity of $40 \%, 60 \%$, and $80 \%$ of one-repetition maximum
$E S=2.25$ - large) was observed for 40\% 1RM. An interaction effect was also revealed for the $60 \% 1 \mathrm{RM}$ intensity $\left(\mathrm{F}_{(11,132)}=3.34, p=0.001, E S=1.72\right.$ - large $)$. Both analyses demonstrated that the sensation of pleasure was reduced in the VF strategy, whereas we did not find any difference for the $80 \% 1 \mathrm{RM}$ intensity $\left(\mathrm{F}_{(11,143)}\right.$ $=0.220, p=0.995, E S=0.10-$ trivial $)$.

\section{Rating of perceived exertion}

Figure 2 shows the results analysed by two-way repeated measures ANOVA for each intensity investigated $(40 \%, 60 \%$, and $80 \% 1 \mathrm{RM})$. An interaction effect

$40 \%$

$60 \%$
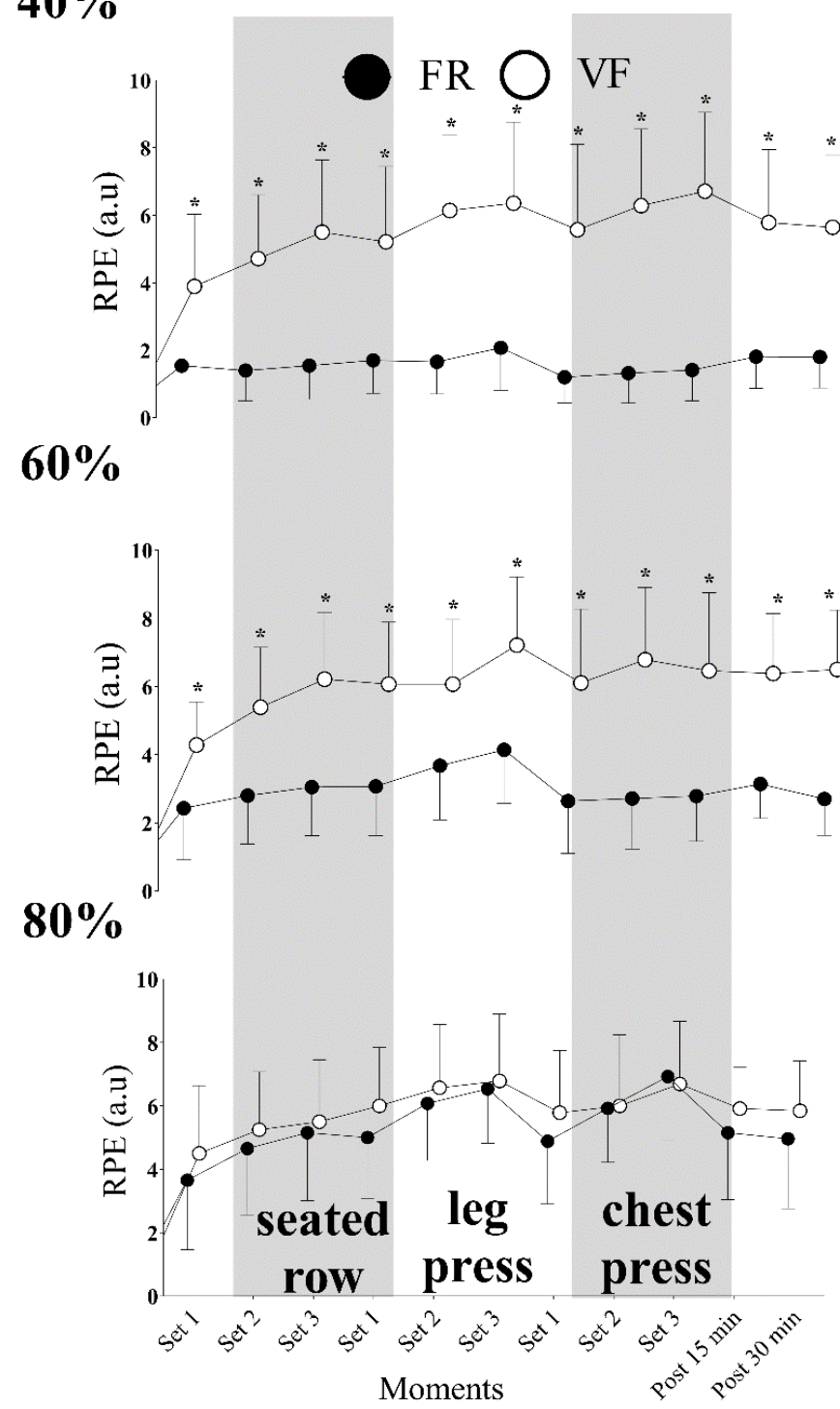

FR - fixed repetition, VF - volitional failure, RPE - rating of perceived exertion, a.u. - arbitrary unit

* The moment between strategies was significantly different $(p<0.05)$

Figure 2. Comparison of RPE in VF vs. FR strategies at the intensity of $40 \%, 60 \%$ and $80 \%$ of one-repetition maximum 
for strategy (VF vs. FR) vs. moment (before the experiment, between all sets, and after the experiment) $\left(\mathrm{F}_{(11,143)}=17.79, p=0.001, E S=5.80-\right.$ large $)$ was observed for $40 \%$ 1RM. An interaction was also revealed for $60 \% 1 \mathrm{RM}\left(\mathrm{F}_{(11,132)}=7.74, p=0.001, E S=\right.$ 2.77 - large), and RPE was increased in the VF strategy in both analyses. However, the results did not indicate an interaction for $80 \% 1 \mathrm{RM}\left(\mathrm{F}_{(11,121)}=1.680\right.$, $p=0.059, E S=0.24-$ trivial).
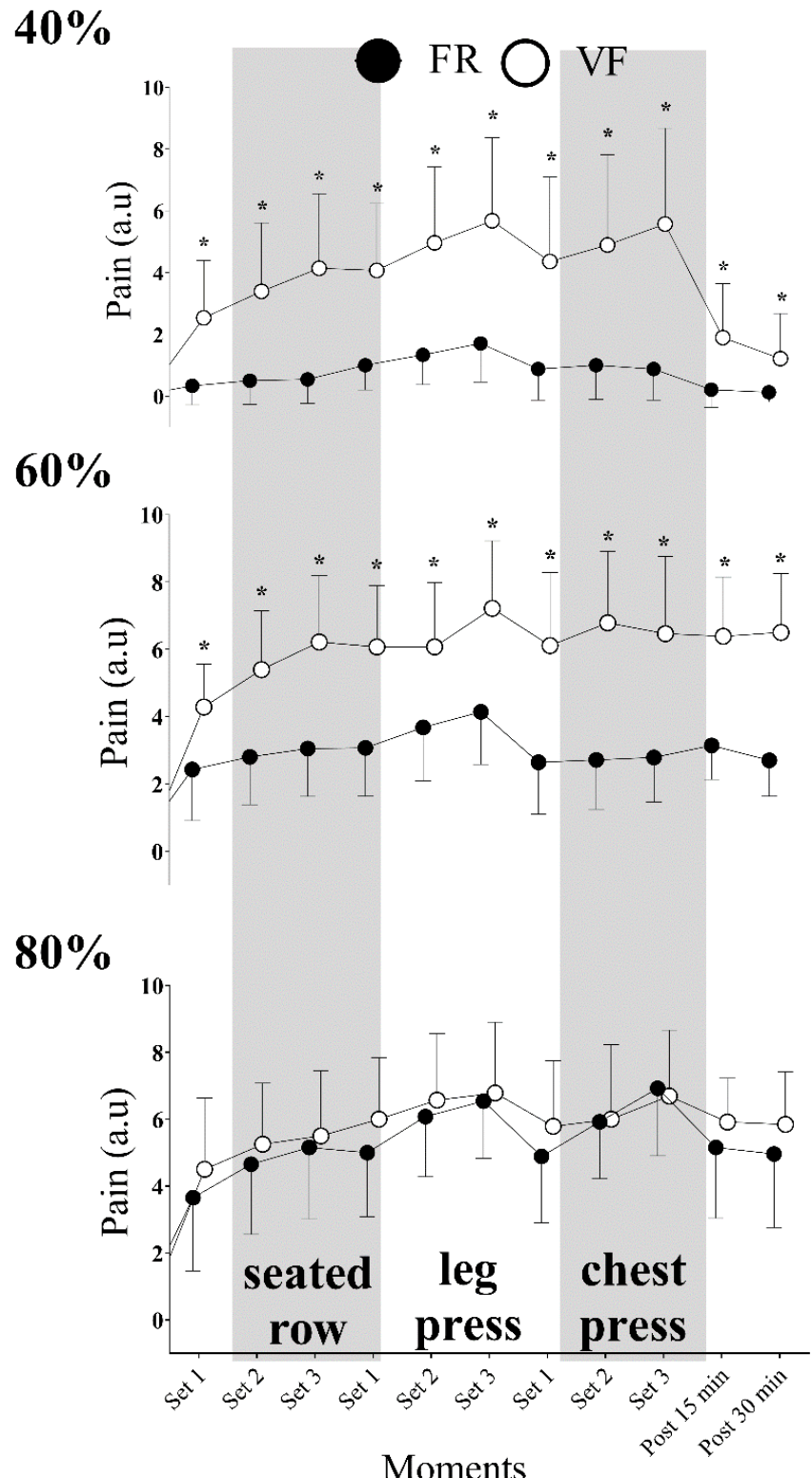

FR - fixed repetition, VF - volitional failure, a.u. - arbitrary unit * The moment between strategies was significantly different $(p<0.05)$

Figure 3. Comparison of perceived pain in VF vs. FR strategies at the intensity of $40 \%, 60 \%$, and $80 \%$ of one-repetition maximum

\section{Pain}

Figure 3 shows the results analysed by two-way repeated measures ANOVA for each intensity investigated $(40 \%, 60 \%$, and $80 \% 1 \mathrm{RM})$. An interaction effect for strategy (VF vs. FR) vs. moment (before the experiment, between all sets, and after the experiment $)\left(\mathrm{F}_{(11,132)}=18.447, p=0.001, E S=1.03-\right.$ moderate) was observed for $40 \% 1 \mathrm{RM}$. Furthermore, an interaction between strategy vs. moment $\left(\mathrm{F}_{(11,121)}=4.88\right.$, $p=0.001, E S=0.77-$ low) was found for $60 \% 1 \mathrm{RM}$.

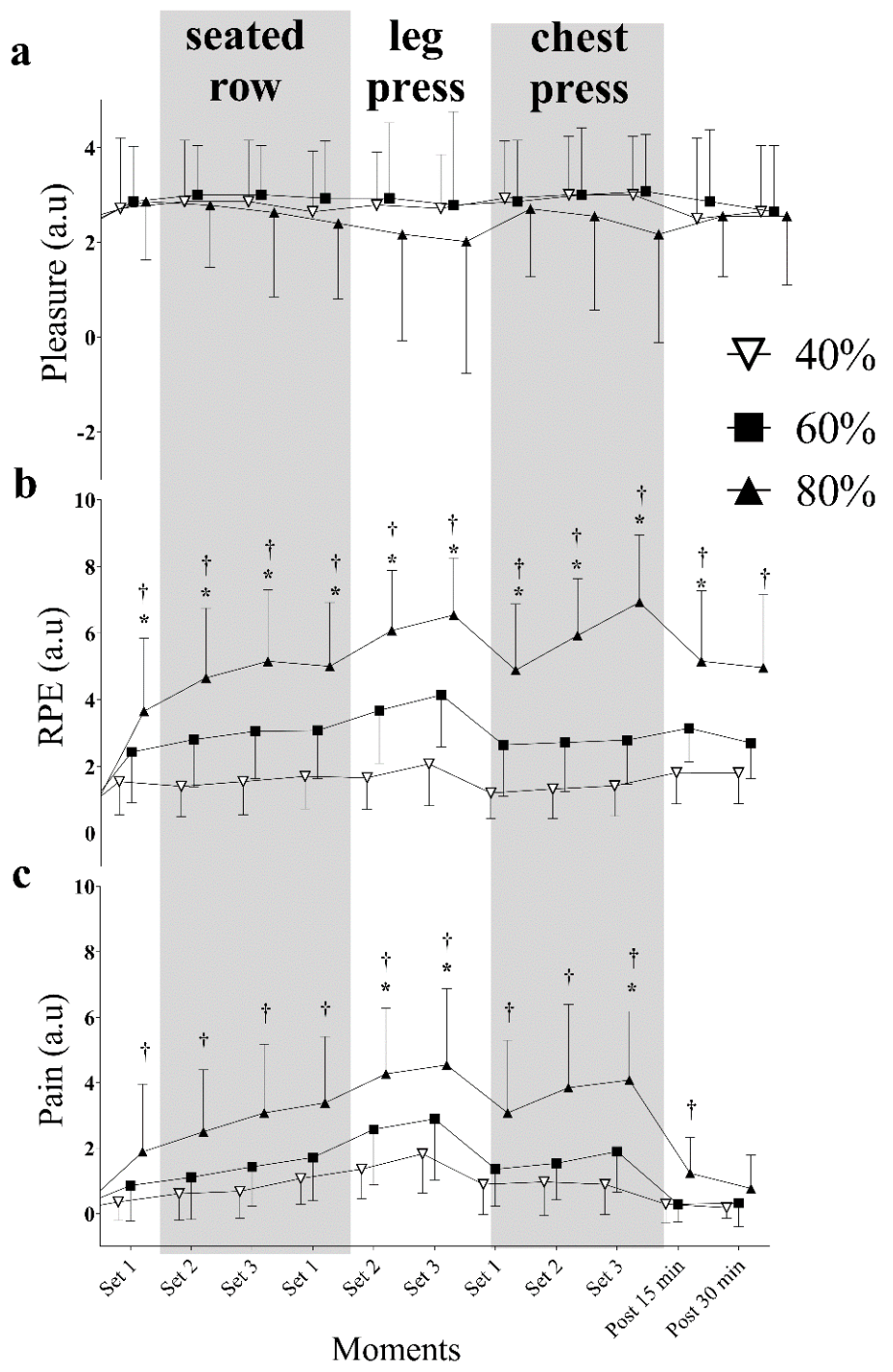

a.u. - arbitrary unit, RPE - rating of perceived exertion ${ }^{*} p<0.05,60 \%$ one-repetition maximum in relation to $40 \%$ onerepetition maximum, $\uparrow p<0.05,80 \%$ one-repetition maximum in relation to $40 \%$ one-repetition maximum

Figure 4. Comparison of $40 \%$ vs. $60 \%$ vs. $80 \%$ one-repetition maximum intensities for (a) pleasure, (b) RPE, and (c) pain 
G.C. Vasconcelos, I. Damorim, T. Santos, D. Lima-Junior, L. Fortes, The pleasure in strength training

An increase in pain for the VF strategy was revealed for both analyses in the comparisons of training strategies. No significant difference was found for $80 \%$ $1 \mathrm{RM}(p>0.05)$.

\section{Intensities ( $40 \%$ vs. $60 \%$ vs. $80 \% 1 \mathrm{RM})$}

The volume regarding intensity comparison $(40 \%$ vs. $60 \%$ vs. $80 \% 1 \mathrm{RM}$ ) was equalized. We found an interaction intensity vs. moment for RPE and pain, which increased at the $80 \%$ intensity $\left(\mathrm{F}_{(22,264)}=10.837\right.$, $p=0.001)$ and $60 \% 1 \mathrm{RM}\left(\mathrm{F}_{(22,264)}=7.286, p=0.001\right)$ compared with $40 \% 1 \mathrm{RM}$ (Figure 4 ). On the other hand, no interaction effect was observed between intensity vs. moment in the pleasure evaluation $\left(\mathrm{F}_{(22,286)}\right.$ $=1.632, p=0.388$ ).

\section{Discussion}

The present study aimed to compare the sensation of pleasure, RPE, and pain in different volumes (VF vs. FR) at the intensities of $40 \%, 60 \%$, and $80 \% 1 \mathrm{RM}$ with equalized volume. The main findings of the study confirmed its hypotheses, namely: (a) the sensation of pleasure responses significantly decreased in $\mathrm{VF}$ training performed at the intensities of $40 \%$ and $60 \%$ 1RM when compared with FR for the same intensity; (b) an increase in RPE and pain perception in VF training at the intensities of $40 \%$ and $60 \% 1 \mathrm{RM}$ was observed when compared with FR at the same intensities, although this finding was not replicated at the intensity of $80 \% 1 \mathrm{RM}$; and (c) the sensation of pleasure did not change when intensities of $40 \%$ vs. $60 \%$ vs. $80 \% 1 \mathrm{RM}$ were compared for FR (equalized volume). These results indicate that the sensation of pleasure was decreased, while RPE and pain perception increased in training with $40 \%$ and $60 \% 1 \mathrm{RM}$ performed in VF when compared with FR.

Strength training studies on pleasure are still inconclusive [7, 11, 12, 31, 32]. In a study involving trained men, Portugal et al. [12] observed a decrease in pleasure only when the high-intensity $(80 \% 1 \mathrm{RM})$ group was compared with the control group (without exercise). In contrast, a difference in pleasure modulation was revealed in the intensity comparisons ( $40 \%$ vs. $60 \%$ vs. $80 \% 1 \mathrm{RM}$ ) for FR. Altogether, these results corroborate the present study. In contrast, a dose-response effect of the sensation of pleasure after physical exercise for different intensities with a greater sensation of pleasure at moderate intensity has already been observed [10]. A decrease in the sensation of pleasure was demonstrated in women trained at high intensity
(70\% 1RM) compared with low intensity (40\% 1RM) [11]. The volunteers in the aforementioned studies performed a fixed number of repetitions, and perhaps this training configuration allowed modulating sensations such as discomfort and displeasure, even if administered at different intensities. Another point to be highlighted is that, according to the theory of behaviour, low intensities maintain positive responses of the sensation of pleasure [33].

However, VF training generates greater discomfort compared with training that does not lead to maximum effort [17]. Thus, the training configuration performed in previous studies may have decreased the sensation of pleasure during the higher intensities because it led participants to the maximum effort compared with the low-intensity and low-volume training. It is also noteworthy that the prescribed RM training is well used by trained males in fitness centres. Moreover, VF might contribute to changes in the perception of pain and effort, consequently decreasing the sensation of pleasure. Thus, we observed a necessity to evaluate the affective responses in VF in different percentages of $1 \mathrm{RM}$.

In fact, the present study is the first to compare the effects of different VF fractions on the sensation of pleasure. The results of this study, comparing intensities (40\%, 60\%, and 80\% 1RM) and using different strategies (VF vs. FR), revealed a significant decrease in the sensation of pleasure in VF compared with FR at the intensities of $40 \%$ and $60 \% 1 \mathrm{RM}$. In this case, the rationale given is that intensity does not modulate the feeling of pleasure in trained men [12]. However, different training configurations should be considered when administered in strength training. These results demonstrate that the sensation of pleasure in strength training is not solely modulated by intensity, but by a high training volume performed in VF. This can be justified by the different neuromuscular, cardiovascular, and biochemical responses to this training strategy when compared with submaximal exercise [14].

The scientific literature points out a relationship between the fraction of $1 \mathrm{RM}$ and RPE responses when the number of repetitions is predetermined [2]. These results are in accordance with the present study, in which a dose-response effect was observed for RPE when compared with intensities $40 \%$ vs. $60 \%$ vs. $80 \%$ $1 R M$ in FR. It is suggested that these results are exclusively related to raised external resistance. However, increased RPE is also observed when the same fraction of 1RM is prescribed for more than 1 set or in different training configurations [3]. Studies have 
shown that training with a low $1 \mathrm{RM}$ percentage in VF potentiates RPE increase compared with a high 1RM\% in VF [4, 34]. Parallel to the aforementioned studies, our paper shows an increase in RPE in VF training at the intensities of $40 \%$ and $60 \% 1 \mathrm{RM}$ when compared with FR. There is possibly a contribution of accumulated metabolites and muscle fatigue due to the training configuration adopted to increase RPE.

Similar to the RPE results, pain perception also increased at the intensities of $40 \%$ and $60 \% 1 \mathrm{RM}$ in VF when compared with FR. Previous studies point to a relationship between pain perception and RPE [27, 35 ] and an increase in pain perception scores with an increase in the number of sets [36, 37]. All the results presented reinforce the idea that the metabolic disturbance has a strong influence on the perceptual responses during strength training owing to the training configuration.

In fact, training sessions administered at the highest $1 \mathrm{RM} \%$, whether applying a maximum number of repetitions or not, did not influence the sensation of pleasure in the trained men. In addition, lower intensities in VF significantly worsened the sensation of pleasure and increased the perception of pain and RPE. Displeasure is apparently not adequate, and this scenario might negatively influence an individual's performance to achieve their goals [38]. According to behaviour theories, it is postulated that there is a decrease in the frequency of the type of training or even demotivation of the practice [33].

Because of the lack of instruments, it was not possible to directly evaluate the concentration of metabolites which could serve as a basis to improve the results and discuss the different training strategies with regard to the sensation of pleasure, pain, and RPE. However, it has been reported that an increase in metabolite concentration influences an increase in pain perception and effort responses [39]. The description of the number of repetitions and the affection responses presented in the study can aid coaches and researchers in programming strength training variables in a practical way. In other words, some people may not like performing at low intensities with high numbers of repetitions, and this type of prescription might keep them from training. However, it is important to note that the sensation of pleasure scale used in the present study is still in the process of cross-cultural validation. Nevertheless, these scales are accepted by researchers in the area to evaluate affective responses.

\section{Conclusions}

This study is the first to empirically demonstrate that VF training sessions at the intensities of $40 \%$ and $60 \% 1 \mathrm{RM}$ decrease affect and significantly increase RPE and perceived pain when compared with the same intensity in FR among trained men. However, the intensity of $80 \% 1 \mathrm{RM}$, regardless of the adopted strategy, maintained a similar affect, probably owing to the equivalence of total work in intensity between the training strategies. Moreover, different intensities were not able to change the affect. Thus, unlike what is seen in aerobic exercise, it seems that the sensation of pleasure in strength training is not related to intensity.

\section{Acknowledgments}

The authors would like to acknowledge the students Amanda Machado Nunes, Luanna Karina Pereira da Silva, Igor Nunes Miranda, and Danielly Marques Ferreira for providing assistance in data collection.

\section{Disclosure statement}

No author has any financial interest or received any financial benefit from this research.

\section{Conflict of interest}

The authors state no conflict of interest.

\section{Funding}

This research was funded by the Coordenação de Aperfeiçoamento de Pessoal de Nível Superior (CAPES).

\section{References}

1. Borg G. Borg's perceived exertion and pain scales. Champaign: Human Kinetics; 1998.

2. Row BS, Knutzen KM, Skogsberg NJ. Regulating explosive resistance training intensity using the rating of perceived exertion. J Strength Cond Res. 2012;26(3): 664-671; doi: 10.1519/JSC.0b013e31822ac367.

3. Hardee JP, Lawrence MM, Utter AC, Triplett NT, Zwetsloot KA, McBride JM. Effect of inter-repetition rest on ratings of perceived exertion during multiple sets of the power clean. Eur J Appl Physiol. 2012;112(8): 3141-3147; doi: 10.1007/s00421-011-2300-x.

4. Pritchett RC, Green JM, Wickwire PJ, Pritchett KL, Kovacs MS. Acute and session RPE responses during resistance training: bouts to failure at $60 \%$ and $90 \%$ of 1RM. S Afr J Sports Med. 2009;21(1):23-26; doi: 10.17159/2078-516X/2009/v21i1a304.

5. Fusco A, Sustercich W, Edgerton K, Cortis C, Jaime SJ, Mikat RP, et al. Effect of progressive fatigue on session RPE. J Funct Morphol Kinesiol. 2020;5(1):15; doi: 10.3390/jfmk5010015. 
G.C. Vasconcelos, I. Damorim, T. Santos, D. Lima-Junior, L. Fortes, The pleasure in strength training

6. Halson SL. Monitoring training load to understand fatigue in athletes. Sports Med. 2014;44(Suppl. 2):S139S147; doi: 10.1007/s40279-014-0253-z.

7. Elsangedy HM, Krinski K, da Silva Machado DG, Dutra Agrícola PM, Okano AH, da Silva SG. Self-selected intensity, ratings of perceived exertion, and affective responses in sedentary male subjects during resistance training. J Phys Ther Sci. 2016;28(6):1795-1800; doi: 10.1589/jpts.28.1795.

8. Ekkekakis P. The dual-mode theory of affective responses to exercise in metatheoretical context: I. Initial impetus, basic postulates, and philosophical framework. Int Rev Sport Exerc Psychol. 2009;2(1):73-94; doi: 10.1080/17509840802705920.

9. Oliveira BRR, Slama FA, Deslandes AC, Furtado ES, Santos TM. Continuous and high-intensity interval training: which promotes higher pleasure? PLoS One. 2013;8(11):e79965; doi: 10.1371/journal.pone.0079965.

10. Arent SM. Resolving dose-response and mechanistic issues in the resistance training and affect relationship: the role of intensity. Med Sci Sports Exerc. 2004;36(5): S95; doi: 10.1249/00005768-200405001-00448.

11. Focht BC, Garver MJ, Cotter JA, Devor ST, Lucas AR, Fairman CM. Affective responses to acute resistance exercise performed at self-selected and imposed loads in trained women. J Strength Cond Res. 2015;29(11): 3067-3074; doi: 10.1519/JSC.0000000000000985.

12. Portugal EMM, Lattari E, Santos TM, Deslandes AC. Affective responses to prescribed and self-selected strength training intensities. Percept Mot Skills. 2015; 121(2):465-481; doi: 10.2466/29.PMS.121c17x3.

13. Ekkekakis P, Parfitt G, Petruzzello SJ. The pleasure and displeasure people feel when they exercise at different intensities: decennial update and progress towards a tripartite rationale for exercise intensity prescription. Sports Med. 2011;41(8):641-671; doi: 10.2165/ 11590680-000000000-00000.

14. Pareja-Blanco F, Rodríguez-Rosell D, Sánchez-Medina L, Ribas-Serna J, López-López C, Mora-Custodio R, et al. Acute and delayed response to resistance exercise leading or not leading to muscle failure. Clin Physiol Funct Imaging. 2017;37(6):630-639; doi: 10.1111/cpf. 12348.

15. Garber CE, Blissmer B, Deschenes MR, Franklin BA, Lamonte MJ, Lee I-M, et al. American College of Sports Medicine position stand. Quantity and quality of exercise for developing and maintaining cardiorespiratory, musculoskeletal, and neuromotor fitness in apparently healthy adults: guidance for prescribing exercise. Med Sci Sports Exerc. 2011;43(7):1334-1359; doi: 10.1249/MSS.0b013e318213fefb.

16. Smith D, Bruce-Low S. Strength training methods and the work of Arthur Jones. J Exerc Physiol Online. 2004; 7(6):52-68.

17. Davies T, Orr R, Halaki M, Hackett D. Effect of training leading to repetition failure on muscular strength: a systematic review and meta-analysis. Sports Med. 2016;46(4):487-502; doi: 10.1007/s40279-015-0451-3.
18. Hollander DB, Durand RJ, Trynicki JL, Larock D, Castracane VD, Hebert EP, et al. RPE, pain, and physiological adjustment to concentric and eccentric contractions. Med Sci Sports Exerc. 2003;35(6):1017-1025; doi: 10.1249/01.MSS.0000069749.13258.4E.

19. Elsangedy HM, da Silva Machado DG, Krinski K, do Nascimento PHD, de Amorim Oliveira GT, Santos TM, et al. Let the pleasure guide your resistance training intensity. Med Sci Sports Exerc. 2018;50(7):1472-1479; doi: 10.1249/MSS.0000000000001573.

20. International Society for the Advancement of Kinanthropometry. International standards for anthropometric assessment. Underdale: ISAK; 2001.

21. Jackson AS, Pollock ML. Generalized equations for predicting body density of men. Br J Nutr. 1978;40(3):497504; doi: 10.1079/bjn19780152.

22. Siri WE. Body composition from fluid spaces and density: analysis of methods. In: Brožek J, Henschel A (eds.), Techniques for measuring body composition. Washington: National Academy of Sciences - National Research Council; 1961; 223-244.

23. Epley B. Poundage chart. In: Boyd Epley Workout. Lincoln: Body Enterprises; 1985; 86.

24. Adams GM. Exercise physiology: laboratory manual. Boston: WCB McGraw-Hill; 1998.

25. Menêses AL, da Silva Santana F, Germano Soares AH, Coêlho de Souza BC, de Azevedo Souza DJC, dos Santos MAM, et al. Validity of one repetition maximum predictive equations vary according to the exercise performed in trained young adults [in Portuguese]. Rev Bras Ativ Fis Saude. 2013;18(1):95-104; doi: 10.12820/ 2317-1634.2013v18n1p95.

26. Hardy CJ, Rejeski WJ. Not what, but how one feels: the measurement of affect during exercise. J Sport Exerc Psychol. 1989;11(3):304-317; doi: 10.1123/jsep.11.3.304.

27. Cook DB, O’Connor PJ, Eubanks SA, Smith JC, Lee M. Naturally occurring muscle pain during exercise: assessment and experimental evidence. Med Sci Sports Exerc. 1997;29(8):999-1012; doi: 10.1097/00005768199708000-00004.

28. Borg G, Borg E. A new generation of scaling methods: level-anchored ratio scaling. Psychologica. 2001;28: 15-45.

29. Foster C, Florhaug JA, Franklin J, Gottschall L, Hrovatin LA, Parker S, et al. A new approach to monitoring exercise training. J Strength Cond Res. 2001;15(1): 109-115; doi: 10.1519/00124278-200102000-00019.

30. Rhea MR. Determining the magnitude of treatment effects in strength training research through the use of the effect size. J Strength Cond Res. 2004;18(4):918920; doi: 10.1519/14403.1.

31. Benites ML, Alves RC, Ferreira SS, Follador L, da Silva SG. Are rate of perceived exertion and feelings of pleasure/displeasure modified in elderly women undergoing 8 week of strength training of prescribe intensity? J Phys Ther Sci. 2016;28(2):407-411; doi: 10.1589/ jpts.28.407. 
32. Vasconcelos GC, de Vasconcelos Costa BD, Damorim IR, Santos TM, Cyrino ES, de Lima-Junior D, et al. Do traditional and cluster-set resistance training systems alter the pleasure and effort perception in trained men? J Phys Educ Sport. 2019;19(Suppl. 3):823-828; doi: 10.7752/jpes.2019.s3118.

33. Rhodes RE, Nigg CR. Advancing physical activity theory: a review and future directions. Exerc Sport Sci Rev. 2011;39(3):113-119; doi: 10.1097/JES.0b013e31821b $94 \mathrm{c} 8$.

34. Shimano T, Kraemer WJ, Spiering BA, Volek JS, Hatfield DL, Silvestre R, et al. Relationship between the number of repetitions and selected percentages of one repetition maximum in free weight exercises in trained and untrained men. J Strength Cond Res. 2006;20(4): 819-823; doi: 10.1519/R-18195.1.

35. Slapsinskaite A, Razon S, Serre NB, Hristovski R, Tenenbaum G. Local pain dynamics during constant exhaustive exercise. PLoS One. 2015;10(9):e0137895; doi: 10.1371/journal.pone.0137895.

36. Astorino TA, Terzi MN, Roberson DW, Burnett TR. Effect of caffeine intake on pain perception during highintensity exercise. Int J Sport Nutr Exerc Metab. 2011; 21(1):27-32; doi: 10.1123/ijsnem.21.1.27.

37. Hudson GM, Green JM, Bishop PA, Richardson MT. Effects of caffeine and aspirin on light resistance training performance, perceived exertion, and pain perception. J Strength Cond Res. 2008;22(6):1950-1957; doi: 10.1519/JSC.0b013e31818219cb.

38. Rathschlag M, Memmert D. Self-generated emotions and their influence on sprint performance: an investigation of happiness and anxiety. J Appl Sport Psychol. 2015;27(2):186-199; doi: 10.1080/10413200.2014.97 4783.

39. Lagally KM, Robertson RJ, Gallagher KI, Goss FL, Jakicic JM, Lephart SM, et al. Perceived exertion, electromyography, and blood lactate during acute bouts of resistance exercise. Med Sci Sports Exerc. 2002;34(3): 552-559; doi: 10.1097/00005768-200203000-00025. 